Article

\title{
Pathways for the Amplification of Agroecology in African Sustainable Urban Agriculture
}

\author{
Cristiana Peano ${ }^{1}$, Stefano Massaglia ${ }^{1}\left[\right.$, Chiara Ghisalberti ${ }^{1}$ and Francesco Sottile ${ }^{2, *} \mathbb{C}$ \\ 1 Dipartimento di Scienze Agrarie, Forestali e Alimentari, University of Torino, Largo Paolo Braccini 2, \\ 10095 Grugliasco, Italy; cristiana.peano@unito.it (C.P.); stefano.massaglia@unito.it (S.M.); \\ chiara.ghisalberti@unito.it (C.G.) \\ 2 Dipartimento di Architettura, University of Palermo, Viale delle Scienze, Edificio 14, 90128 Palermo, Italy \\ * Correspondence: francesco.sottile@unipa.it
}

Received: 12 March 2020; Accepted: 29 March 2020; Published: 30 March 2020

\begin{abstract}
A growing awareness that highly intensified agricultural systems have made a substantial worldwide contribution to the worsening of the resilience capacity of natural ecosystems has, over the last twenty years, brought general attention to agroecological management models. This aspect is even more evident in industrial agriculture, which is based on the use of multiple chemical products derived from non-natural synthesis. In more developed countries, a new idea of ecology linked to agricultural production has been increasingly developed and, for this reason, there has been a greater diffusion of differentiated agricultural models taking into consideration the environmental impact of production choices and policies addressed to the conservation of natural resources. In urban agricultural production, it is even more important to adopt resilient production models that, in addition to developing responsible production paths and allowing a positive connection with the needs of consumers, guarantees reasonable and positive behaviors respecting the environment in which most of the urban population lives; in other words, the implementation of goal 12 of the sustainable development goals (SDG \#12 Responsible Production and Consumption) of the United Nations. In this work, we report some case studies inspired by the activities carried out by the Slow Food Association in Africa and demonstrate the importance of agroecological models in small-scale agricultural systems, related to the development of school and community gardens in small urban areas of different African countries, as a tool for integrating agricultural activities aimed at social resilience and the conservation of ecosystems.
\end{abstract}

Keywords: urban small-scale agriculture; school garden; community garden; Africa

\section{Introduction}

At present, agroecology lies at the center of the political debate on agriculture. In fact, in 2018, the FAO (Food and Agricultural Organization of the United Nations) affirmed that a majority of the sustainable development goals (SDG) of the United Nations can be reached through agroecology and, furthermore, that it can transform agri-food systems [1]. Although this affirmation has been received positively, the various ways that it has been interpreted differ widely, according to the interest group involved. For example, Levidow et al. [2] emphasized how often the term agroecology is used when talking about solutions that are really much closer to the concepts of climate smart agriculture (CSA) and sustainable agricultural intensification (SAI) [3], with the idea that these strategies can be integrated with the principles of agroecology, along with other approaches including transgenic crops, conservation agriculture, fertilizer and herbicide micro-dosing, and integrated pest management [4]. In a recent article, Pimbert [5] clearly summarized the history of agroecology and emphasized how the core idea in agroecological systems is imitation of the biodiversity and functioning of natural 
ecosystems. This can be distilled into a closed view of nutrient cycles, the use of natural processes for pest control, and biodiversity conservation. Furthermore, agroecological processes include the integration of annual and polyannual plant species with livestock (agroforest-grazing systems), food production in forests (agroforestry systems), and the cultivation of multiple crops on a plot of land (polyculture systems). This approach began to interest researchers as early as the beginning of the 1900s and, by mid-century, the research of Hernández Xolocotzi [6] emphasized the necessity of intercultural processes in achieving agroecological knowledge, combining ecology with experiential knowledge. Since then, many scholars have carried out groundbreaking work in agroecology, such as Miguel Altieri [7] and Stephen Gliessman [8] in the United States, with approaches rooted in ecological science, and Rabhi [9] in France and in Western Africa. Rabhi's approach is based on ecology and is explicitly based on the tradition of anthroposophy and native worldviews, emphasizing an ethic that prioritizes life on planet Earth and not just the agroecosystem. Today, the definitions of agroecology given by Francis et al. [10] and Gliessman [11] go beyond this specific view, leaving the concrete spatial scale (farm or cultivated plot) and entering into the holistic dimension of the food system. This new dimension includes the local, regional, national, and global geographic scales, as well as food production systems, societies, economic systems, and politics. These are all aspects that cannot be directly attributed to a distinct scale, but which are connected and interwoven in different ways.

Furthermore, the relationship between the application of agroecological systems and the ability to overcome extreme climate events and to face them with resilience has become increasingly relevant. Holt-Giménez [12] published an in-depth study carried out in South America following the passage of Hurricane Mitch in Nicaragua, showing that the presence of agroecological models was clearly associated with lower vulnerability and greater sustainability. At the same time, the ability to contribute to a form of climate change mitigation [13], as well as to favor the recovery of land impoverished by conventional agriculture [14], have often been attributed to agroecology.

\section{Africa and Agroecology}

Most of the world's food (72\% of the total) is grown and harvested by 2.5 million small farmers in family farms less than a hectare in size [15]. Local food systems based on these small farms provide the basis for the nutrition, income, economy, and population of the majority of the world. In Africa, agriculture is the most important sector in the economy [16-18], with about $65 \%$ of the total workforce involved and responsible for about 32\% to the continent's gross domestic product (GDP) $[18,19]$. Africa's (and especially Western Africa's) principal characteristics are the extreme diversification of crops, a significant presence of biodiversity, and the importance of social relationships within rural populations. Farms are generally small with little mechanization. Most of the farmers practice low external input agriculture, with limited use of fertilizers and synthetic pesticides. Even at the level of a single farm, farmers typically grow 10 or more crops, which vary according to their layout, soil, topographic position, and climate. In these areas, plant crops are rain-fed and, therefore, are highly vulnerable to climate change, which manifests in the form of unpredictable precipitation and high temperatures. The five principal crops of Western Africa are (in millions of hectares) millet (16.0), sorghum (14.3), cowpea (10.3), corn (7.8), and rice (5.7) [20]. The productivity and profitability of these important crops has been put into question by a decline in soil fertility [21] and the expected impacts of climate change (among other factors). Thus, it is fundamentally important to imagine strategies for sustainable development for Africa, which must take into consideration both adaptation to climate change as well as mitigation of its effects. For this reason, the agroecological model has been proposed and discussed over the past ten years, especially in Africa, together with the topics of resilience and mitigation of the increasingly anomalous and frequent effects of climate change.

In addition to representing a developmental model for agriculture, it takes on even more relevance in small urban centers where, in view of urban horticulture, the cultivation of vegetables and fruit trees plays an essential role for the subsistence of small groups of families who act in a communal way. 
In 1985, Pierre Rabhi created an agroecology educational center in Gorom-Gorom, Burkina Faso, tied to the issue of food sovereignty and with a particular interest in indigenous farmer's knowledge, thus recognizing the importance of ethical science and of the people's knowledge in satisfying fundamental human needs in a way that is culturally unique and respectful of the environment [22].

Agroecology has become explicitly tied to food sovereignty and has involved networks of farmers, social networks, and NGOs (non-governmental organizations); this connection was explicitly stated in what is known as the Declaration of Nyeleni, drafted in 2007 in Mali, for which more than 500 representatives from 50 nations came together:

Food sovereignty is the right of peoples to healthy and culturally appropriate food produced through ecologically sound and sustainable methods, and their right to define their own food and agriculture systems. It puts those who produce, distribute, and consume food at the heart of food systems and policies, rather than the demands of markets and corporations. It defends the interests and inclusion of the next generation. It offers a strategy to resist and dismantle the current corporate trade and food regime, as well as directions for food, farming, pastoral, and fisheries systems determined by local producers. Food sovereignty prioritizes local and national economies and markets and empowers peasant and family farmer-driven agriculture, artisanal fishing, pastoralist-led grazing, and food production, distribution, and consumption based on environmental, social, and economic sustainability. Food sovereignty promotes transparent trade that guarantees just incomes to all peoples, as well as the rights of consumers to control their food and nutrition. It ensures that the rights to use and manage lands, territories, waters, seeds, livestock, and biodiversity are in the hands of those of us who produce food. Food sovereignty implies new social relations free from oppression and inequality between men and women, peoples, racial groups, social and economic classes, and generations. [23]

Today, as a consequence of the high vulnerability of the African populations to climate change, it is necessary to implement adaptations to the existing agricultural systems in new contexts of urban agriculture. Even in this case, the agroecological proposition is based on the integration of the knowledge of African farmers, developed in urban areas and in constant adaptation to climate variability, and the modern science of ecology towards the sustainable management of natural resources and population growth [24].

Crop diversification, which is at the foundation of African family farming, is also the foundation of the agroecological model. In fact, these systems demonstrate resilience, as defined by the IPCC (Intergovernmental Panel on Climate Change) in 2012:

The ability of a system and its component parts to anticipate, absorb, accommodate, or recover from the effects of a hazardous event in a timely and efficient manner, including through ensuring the preservation, restoration, or improvement of its essential basic structures and functions. [25]

In a report made by Coordination Sud [26], the African continent is subdivided into four climate zones, each one with a list of its traditional agroecological practices (e.g., Jessour irrigation in arid zones and zai techniques in sub-arid and sub-humid zones) as well as a series of widespread practices, such as composting, crop rotation, and polyculture. Furthermore, the political approach to ecology adopted in Malawi is also relevant to agroecology and climate change. A study examining the concept of coproduction of knowledge analyzed how small farmers know, perceive, share, and apply knowledge of a changing climate and which resources they access for agroecological methods in this context [27]. In Mali [28], the cultivation of perennial cereals has allowed farmers to spend less on seeds. Food security improvements could be an important instrument in increasing female farmer's access to land and to natural resources, as well as improving soil quality, reducing labor at the beginning of the rainy season, and yielding more resources from uncultivated land. Even in Uganda, agroecology has been gaining ground in the debate on how to address the systemic social and environmental problems in agriculture. In particular, Isgren and Ness [29] studied the case of a citizen's network that connects groups of farmers and nongovernmental organizations at different levels. In this case, 
agroecology is directed at small farmers with an approach that seeks technology appropriate for the local level and suggests participatory methods for research and technical assistance. These studies indicated that agroecology stimulates the improvement and strengthening of a collective organization of farmers $[23,29]$ and knowledge exchange; for example, the participatory actions promoted by Farmer Field Schools, in which farmers contribute to education on agroecological practices and where multi-stakeholder research platforms are developed that take into consideration the expectations of farmers [24]. Thus, it is possible to affirm that, in contrast to most conventional agricultural research and development, agroecological approaches in urban environments seek to combine the experiential knowledge of farmers and indigenous populations with the latest discoveries from ecological science [30,31]. Local knowledge and native management systems can, thus, be considered as the starting point for efficient solutions to the challenges and opportunities specific to each. Thus, it is important to amplify the agroecological approach and thereby reach the largest number of people possible with this message, especially small farmers, their families, and their communities throughout the world [11].

In this study, we analyze the effects of a project launched in Africa by the Slow Food Association in 2010, aiming at disseminating and amplifying the agroecological approach as a model of small-urban agriculture.

\section{The Case Study}

Background

Slow Food is an international association, founded in Italy in 1986. It has stood out since its inception due to the attention that it gives to local landscapes and cultures and for its desire to spread food culture and food sovereignty to the greatest number of people possible. These philosophies allow the association to perceive the incipient effects of globalization on daily food in terms of variety, quality, and taste [32].

This greater understanding of the raw materials that come to the table leads to an understanding of the importance and urgency of safeguarding biodiversity, traditional/agroecological models, and promoting the work of those who preserve it. This approach has allowed Slow Food to group together problems that are usually studied and managed separately, including environmental, agricultural, social, cultural, and economic issues.

In this approach, the association is able to involve subjects from quite different backgrounds, with different experiences, and from different fields (i.e., university professors, agronomists, veterinarians, teachers, chefs, small-scale producers, and consumers); in particular, the small producers (farmers, breeders, and small-scale artisans) who are the real custodians of agrobiodiversity. They protect plant varieties, animal breeds, and traditional agronomic techniques in every corner of the planet through their own knowledge and daily labor. The economic sustainability of the efforts of these biodiversity custodians is a sine qua non condition for their survival, which can only be ensured through their fair payment. In this context, the agroecological approach is fundamentally important because it promotes and involves local small growers in order to safeguard the agricultural landscape as well as local traditional architecture.

\section{Community and School Gardens Project}

Considering the above discussion, the Slow Food Foundation launched a campaign, in 2004, based on the application of the cardinal concepts in its philosophy, even in developing countries. Every form of agricultural biodiversity preservation and agroecological practice can result in the birth of new ways of development [33]. This soft development might be slower with a more modest annual growth-rate; however, it is more widespread and is connected to the vocation of the region and population. This campaign also pursues the mitigation of one of globalization's largest risks, cultural homogenization, which is a loss or appreciation of individual identity. Instead, slow development is 
proposed with a renewed respect for the heterogeneous needs of the various groups of beneficiaries, carried out through cultural mediation and a bottom-up approach, the activation and reinforcement of local networks (production of social capital) and, finally, an innovative management approach that entrusts projects entirely to local networks.

Part of this campaign is the "10,000 Gardens in Africa" project [34], whose approach is tied to the principles of agroecology. It relies on the knowledge of local and urban farmers; on the application of traditional and modern techniques that have been adapted to different agricultural, pedological, and climate conditions; on the correct management of natural resources (e.g., biodiversity, soil, and water); and on social equity. The project involves all social strata, especially small farmers, schoolteachers and students, urban horticulturalists, and especially women, as they are often the ones who are principally responsible for what their family eats. In this project, the urban gardens are divided according to their specific typology: There are school gardens that have been created on a land belonging to a school where teachers and students can jointly work during some of their hours at school. In these cases, the fruits and vegetables collected in the garden can be used in the school canteen, or taken home by the students. A community garden, on the other hand, is created on land that often belongs to the municipality and is managed (commonly or in separated plots) by a community of people (or families) who share technical choices, cultivation techniques, and sometimes even the purchase of tools for agriculture. The products are specifically used by the families working in the garden and the surplus can be sold at the market.

The project is well-developed in the countries where the Slow Food network is already strong: Today, several organizations exist in many African countries (associations, farming co-operatives, NGOs, and so on) that build vegetable gardens and spread forms of sustainable farming. The "10,000 Gardens in Africa" [34] project begins from these valuable experiences, launches new ones, puts the participants involved into a network, and further explores aspects, such as seed production and the use of sustainable farming techniques. School gardens are one of the most important instruments Slow Food has in promoting nutritional and environmental education in schools and in communities. In particular, they facilitate the transmission of food culture, environmental preservation (which has become more and more important in urban areas), and agroecology to younger generations.

\section{Methodology}

The advantages of agroecology and of diversified systems have been systematically undervalued by classic indicators in agriculture (such as productivity) that, in particular, do not take into consideration social aspects such as the transmission of knowledge between generations. Once recognized, this stimulated research on a series of indicators that were better suited to agroecology; that is, to socio-ecological systems. A wider range of indicators to evaluate the efficiency and the success of these systems were, thus, elaborated; especially those regarding sustainability, such as that already developed by Peano et al. with the SAEMETH method [35].

In particular, the SAEMETH-G method [36] was used as a reference in our study. This method was developed by taking into consideration the triple bottom line of social, environmental, and economic sustainability.

The indicators used were selected by 15 stakeholders (professors, teachers, researchers, agronomists, managers of co-operative development projects, and NGOs), and were meant to demonstrate the long-term sustainability of an agroecosystem; biodiversity conservation; ecosystemic services; interactions between agriculture and the economy regarding equality; resilience of natural systems and the community not just in the face of change (i.e., not just climate); food security; and nutrition. In other words, all that which is important for the creation of sustainable food systems.

The construction of the framework moved across three levels of increasing complexity: first, the selection of the sustainability dimensions; then, the individuation of the components; and, finally, the choice of proper indicators, as described in Table 1. 
Table 1. The structure of the framework.

\begin{tabular}{cccc}
\hline Level 1: Dimension & Socio-Cultural & Agro-Environmental & Economic \\
\hline Level 2: Component & $\begin{array}{c}\text { Internal relationships, } \\
\text { external relationships }\end{array}$ & $\begin{array}{c}\text { Biodiversity, } \\
\text { culture/terroir, farming } \\
\text { practices, productive } \\
\text { process, energy }\end{array}$ & External input, selling \\
\hline $\begin{array}{c}\text { Level 3: Indicator } \\
\text { (number of indicators) }\end{array}$ & 19 & 22 & 9 \\
\hline
\end{tabular}

Regarding the weight of the dimensions, the outcome of the exchange between research stakeholders during the first focus group was to attribute equal importance (equal weight $=$ maximum 100 for each measurement) to each of the three dimensions in the total measure of sustainability. The definition of the components and the attribution of weights to the components (Level 2) of the various dimensions using the equal weights system led to the following outcomes:

- for the socio-cultural dimensions: two components were selected (internal and external relationships), each with weight equal to 50;

- for the agro-environmental dimensions: five components were selected (biodiversity, culture/terroir, farming practices, productive process, and energy), each with weight equal to 20; and

- for the economic dimensions: two components were selected (external input and products sold), each with a weight of 50 .

By following the approach used in the formulation of SAEMETH [32], already successfully applied by Van Calker et al. [37] and Meul et al. [38], the research team tried to mediate the subjectivity of the school garden sustainability components in order to create a framework that allowed data collection to be standardized and for results to be comparable.

Data were collected for each urban garden with the same methodology [32] during two visits, lasting about three hours each (interviews were conducted with at least $30 \%$ of the people involved), including a meeting with the project manager on site conducted by an expert trained in the method. The training program was carried out in Italy during the Terra Madre event in 2016 [39]. English or French was used as the reference language. The interviewer was always accompanied by an interpreter, who translated the questions into the local dialect. In this way, no language misunderstandings were observed.

Once the data had been collected, they were first graphically analyzed, similarly to the SAEMETH approach [35], by putting dimensions, components, and indicators together, such that they could be summarized both singularly and as a whole, considering different scales of analysis (e.g., a number of school gardens, a single school garden, a single dimension, or a single component). In this work each dimension has a minimum value of 0 (unsustainable) and a maximum value of 1 (sustainable) and, consequently, the overall score can vary in a range from 0 to 3 .

Up until now, about 3117 gardens in 34 African countries have been created. In this latest evaluative study of sustainability, 83 gardens were taken into consideration, spread throughout 7 of the nations that are considered amongst the most active within the Slow Food network in participating in the "10,000 Gardens in Africa" project [34]: Burkina Faso, Madagascar, Rwanda, Uganda, Ghana, Kenya, and Tanzania.

The analyzed gardens are comprised of both school and community spaces in urban areas, representing about $10 \%$ of the gardens present in all of the countries taken into consideration. 


\section{Results}

\section{School Gardens}

The majority of the 39 school gardens taken into consideration in this study (26) reached a total sustainability score between 1.5 and 2 . Only one garden arrived at a total sustainability score over 2 , while the remaining 12 gardens were between 1 and 1.5 .

The garden with the highest score was Mbuyuni, in Tanzania. It is located in Dar Es Salaam and was launched in 2012. It is managed by one of the most active Slow Food groups present in the area and is supported by an important local organization. This garden, especially on the social and economic fronts, has achieved notable sustainability values.

In comparison, almost all of the gardens considered in this study that registered low total sustainability values are in Uganda. Notwithstanding the fact that they are many and that they began well, the school gardens in Uganda show many deficiencies from social, environmental, and economic points of view. Many of the gardens lack a connection and direct contact with the local Slow Food network and all of the gardens only passively involve young people and women. A discrete core was observed in the components related to agro-environmental fields, meanwhile, in the economic field, none of the considered school gardens sold any products.

In an analysis of the single scales (Table 2), the social scale reached a sustainability score, on average, near 0.72. Furthermore, the fairly homogenous trend of this scale's values among the different analyzed gardens (coefficient of variation 0.157 ) is also apparent. The "10,000 Gardens in Africa" project [34] strongly believes in the educational and formative value of school gardens: For this reason, it has invested numerous resources towards strengthening and developing these projects over the years, seeing them as a stimulus to involve and make aware not just children, but also teachers, families and, in many cases, the entire community. The foundational methodology is garden-based learning, an instructional strategy that uses gardens as a resource and a teaching tool, as described by Williams et al. [40]. The work that was carried out (and continues to be carried out every day) on a social level is important, and the results show it. These efforts contribute to the promotion of knowledge and the transmission of skills, making school gardens virtuous examples for examining and rethinking the world around us and not just providing sustenance.

Table 2. School gardens: single-scale analysis of the sustainability score reached in each country.

\begin{tabular}{|c|c|c|c|c|c|c|c|c|c|c|c|c|c|}
\hline \multirow{2}{*}{ Country } & \multirow{2}{*}{$\begin{array}{c}\text { School } \\
\text { Gardens } \\
\text { (N.) }\end{array}$} & \multicolumn{3}{|c|}{ Socio-Cultural } & \multicolumn{3}{|c|}{ Agro-Environmental } & \multicolumn{3}{|c|}{ Economic } & \multicolumn{3}{|c|}{ Total } \\
\hline & & Mean & $\begin{array}{c}\text { Standard } \\
\text { Dev. }\end{array}$ & $\mathrm{CV}$ & Mean & $\begin{array}{c}\text { Standard } \\
\text { Dev. }\end{array}$ & $\mathrm{CV}$ & Mean & $\begin{array}{l}\text { Standard } \\
\text { Dev. }\end{array}$ & $\mathrm{CV}$ & Mean & $\begin{array}{c}\text { Standard } \\
\text { Dev. }\end{array}$ & $\mathrm{CV}$ \\
\hline Burkina Faso & 3 & 0.800 & 0.026 & 0.033 & 0.393 & 0.012 & 0.029 & 0.543 & 0.199 & 0.365 & 1.737 & 0.211 & 0.122 \\
\hline Ghana & 7 & 0.632 & 0.025 & 0.040 & 0.701 & 0.038 & 0.055 & 0.319 & 0.118 & 0.371 & 1.651 & 0.154 & 0.093 \\
\hline Kenya & 5 & 0.800 & 0.022 & 0.028 & 0.608 & 0.089 & 0.147 & 0.410 & 0.014 & 0.034 & 1.818 & 0.108 & 0.060 \\
\hline Madagascar & 4 & 0.768 & 0.073 & 0.095 & 0.428 & 0.076 & 0.179 & 0.495 & 0.172 & 0.348 & 1.690 & 0.254 & 0.150 \\
\hline Rwanda & 5 & 0.664 & 0.088 & 0.133 & 0.460 & 0.108 & 0.236 & 0.544 & 0.161 & 0.297 & 1.668 & 0.241 & 0.145 \\
\hline Tanzania & 5 & 0.866 & 0.119 & 0.137 & 0.420 & 0.064 & 0.153 & 0.502 & 0.199 & 0.397 & 1.788 & 0.186 & 0.104 \\
\hline Uganda & 10 & 0.650 & 0.097 & 0.149 & 0.484 & 0.035 & 0.072 & 0.267 & 0.042 & 0.159 & 1.401 & 0.113 & 0.081 \\
\hline Total & 39 & 0.719 & 0.113 & 0.157 & 0.515 & 0.122 & 0.236 & 0.405 & 0.163 & 0.402 & 1.639 & 0.220 & 0.134 \\
\hline
\end{tabular}

The three gardens with the highest sustainability were in Tanzania $(4437,9442,9444)$. In all three cases, the gardens were supported by two local, well-structured social groups, namely convivia, that had been well-established for some time. In fact, one had existed since 2008, thus showing social dynamics that are well-consolidated, both in terms of internal and external relationships. Decidedly high scores with low variability were also seen in Kenya and in Burkina Faso.

Regarding the agro-environmental scale, this reached an average sustainability score equal to 0.51 with a distribution of values that was uniform on average. Although the agro-environmental and agro-technical scores seem qualitatively uniform, in general there were still low sustainability values (similarly to the community gardens). Thus, we must reiterate that there are still many aspects that still 
need to be worked and implemented in this area to reinforce the agroecological values of the "10,000 Gardens in Africa" project [34].

Among the gardens with the lowest scores (0.4) in this scale, two gardens were in Tanzania, one garden was in Madagascar, and one garden was in Rwanda. The components with the lowest scores include biodiversity, which shows the necessity of implementing and better reinforcing crop diversification in the gardens and of promoting an attentive defense of biodiversity.

The gardens with the highest scores were four gardens in Ghana and one garden in Kenya (6740, $6397,3718,9114,6804)$. Their agro-environmental scores were more than 0.7 with very low coefficients of variation. The Ghana school gardens in the "10,000 Gardens in Africa" project [34] were built where the "Ghana School Feeding Program" [41] is present-a national school lunch program. This program's objectives are fostering school participation, reducing hunger and malnutrition, and improving and increasing crops and their yields. It shares a set of commonalities with "10,000 Gardens in Africa" [34] and the two initiatives have been developed in synergy. Similar to the gardens in Ghana, the garden in Kenya (3718) that achieved one of the highest scores is part of a similar national program (4K clubs), which proposes agricultural activities in schools with the aim of promoting knowledge and practical skills. This garden was honored as the best $4 \mathrm{~K}$ club project in the whole country due to the admirable results that it had achieved regarding experimentation and agro-environmental practices. In fact, Slow Food considers it to be a model garden. In general, Kenyan children in various projects seemed to understand and have experience of the whole process of growing crops, from seeds to food on a plate [42].

Finally, the economic scale showed an average sustainability score of 0.4 , with an evident fluctuating trend that was much more discontinuous in comparison to the other two scales considered (coefficient of variation 0.40). As already shown for community gardens, one of the aspects that most affected the variability of the results of this score was the sale of produce: The sale of surplus yield, in varying proportions with respect to the garden's entire yield, is a component that varied greatly from project to project. In many school gardens, the only economically sustainable objective that is pursued is to produce primary material that can be used to supply the school canteen, as already seen in Kenya and Tanzania in other programs [43]. The sale of surplus only occurred in some cases, where schools pursued additional income in order to achieve a level of added economic sustainability.

Among the gardens that reached higher economic sustainability values (but with coefficients of variability that were also high) were those in Rwanda, Burkina, Tanzania, and Madagascar. In some of these gardens, both components of the economic scale reached high sustainability values, thanks to similar dynamics and characteristics (i.e., the presence of owned land, the acquisition of a minimum amount of input, and the external sale of a well-balanced quantity of surplus in respect to the entire crop yield). On the contrary, the Ugandan gardens showed lower economic sustainability values associated with a low coefficient of variability; low values but with a high coefficient of variability were seen in Ghana; and medium values and a low coefficient of variability were seen in Kenya.

\section{Community Gardens}

It is possible to show that the majority of gardens ( 25 out of 44 ) reached a sustainability score between 1.5 and 2. Only 10 gardens had a total score over 2, while the rest of the gardens (9) were placed between 1 and 1.5 (data not shown but available from the authors).

Among the gardens that achieved higher scores, four were gardens created in Kenya (i.e., almost all of the community gardens analyzed in this nation). This result shows how the presence of a Slow Food network that has been consolidated over the years has had a positive effect on the creation and management of the "10,000 Gardens in Africa" project [34]. Furthermore, the technical and logistic support of some of the local organizations positively affected the success of the initiative.

Even the three community gardens taken into consideration in this study in Ghana showed a total sustainability value equal to or more than 2 . These gardens achieved good results in all three 
sustainability scales considered and have homogenous characteristics: they are located in the same area of the nation, they were launched in 2014, and all receive support from an important local organization.

In contrast, among the gardens that showed low sustainability values, there were two gardens in Uganda that had a decidedly low score, both at the social and economic levels. Both gardens were recently created, can be found in the same region of the country, and are characterized by the same social and agro-environmental dynamics. Most of all, this shows the necessity of working on the social aspect (with respect to the internal and external relationships) in these gardens (data not shown but available from the authors).

By analyzing the entirety of the results obtained in the community gardens subdivided by a single scale (Table 3), one can observe that the social scale reached, on average, a sustainability score equal to 0.708 with an average coefficient of variation that shows a starkly fluctuating trend among the different studied gardens: In fact, the social scale is affected by the project activity in the least homogenous and uniform way, due to the many variables and dynamics that can affect it. In many cases, the groups that animate community gardens are pre-existent (i.e., created before the "10,000 Gardens in Africa" project [34] was launched) and, therefore, further distinguish themselves in terms of their internal and external relationships, as already shown by Roberts and Shackleton [44] in a study in medium-sized towns of the Eastern Cape, South Africa. The social sustainability scale reached its lowest values in 3 of the 10 gardens analyzed in Uganda (with a medium-high coefficient of variation) and higher values in two Kenyan gardens (high values and low variability).

Table 3. Community gardens: single-scale analysis of the sustainability score reached in each country.

\begin{tabular}{|c|c|c|c|c|c|c|c|c|c|c|c|c|c|}
\hline \multirow{2}{*}{ Country } & \multirow{2}{*}{$\begin{array}{l}\text { Community } \\
\text { Gardens } \\
\text { (N.) }\end{array}$} & \multicolumn{3}{|c|}{ Socio-Cultural } & \multicolumn{3}{|c|}{ Agro-Environmental } & \multicolumn{3}{|c|}{ Economic } & \multicolumn{3}{|c|}{ Total } \\
\hline & & Mean & $\begin{array}{l}\text { Standard } \\
\text { Dev. }\end{array}$ & $\mathrm{CV}$ & Mean & $\begin{array}{l}\text { Standard } \\
\text { Dev. }\end{array}$ & $\mathrm{CV}$ & Mean & $\begin{array}{l}\text { Standard } \\
\text { Dev. }\end{array}$ & $\mathrm{CV}$ & Mean & $\begin{array}{c}\text { Standard } \\
\text { Dev. }\end{array}$ & $\mathrm{CV}$ \\
\hline Burkina Faso & 9 & 0.730 & 0.086 & 0.118 & 0.377 & 0.054 & 0.144 & 0.517 & 0.167 & 0.322 & 1.623 & 0.224 & 0.138 \\
\hline Ghana & 3 & 0.750 & 0.046 & 0.061 & 0.657 & 0.093 & 0.141 & 0.685 & 0.061 & 0.089 & 2.092 & 0.102 & 0.049 \\
\hline Kenya & 5 & 0.858 & 0.053 & 0.061 & 0.584 & 0.096 & 0.164 & 0.664 & 0.230 & 0.346 & 2.106 & 0.245 & 0.116 \\
\hline Madagascar & 8 & 0.688 & 0.123 & 0.179 & 0.523 & 0.062 & 0.118 & 0.635 & 0.125 & 0.197 & 1.845 & 0.241 & 0.130 \\
\hline Rwanda & 4 & 0.658 & 0.062 & 0.094 & 0.598 & 0.172 & 0.289 & 0.525 & 0.179 & 0.341 & 1.780 & 0.362 & 0.204 \\
\hline Tanzania & 5 & 0.650 & 0.185 & 0.285 & 0.554 & 0.079 & 0.142 & 0.668 & 0.105 & 0.158 & 1.872 & 0.297 & 0.158 \\
\hline Uganda & 10 & 0.668 & 0.178 & 0.267 & 0.507 & 0.065 & 0.129 & 0.4614 & 0.153 & 0.333 & 1.636 & 0.297 & 0.182 \\
\hline Total & 44 & 0.708 & 0.135 & 0.191 & 0.516 & 0.113 & 0.219 & 0.572 & 0.168 & 0.295 & 1.796 & 0.302 & 0.168 \\
\hline
\end{tabular}

As far as the agro-environmental scale, it reached an average sustainability value equal to 0.52 . It is possible to show how the "10,000 Gardens in Africa" project [34] uniformly affected technical and agro-environmental aspects, thanks to a unilaterally consistent effort carried out with handbooks; communication and interaction between the International Slow Food office and local working groups; and the education and on-site training of consultants, technicians, and the community through learning opportunities in the gardens and local food systems [45].

In general, the results that have been achieved are still weak and, thus, merit being reinforced and improved. Among the gardens that achieved the lowest sustainability values ( 0.377 with a coefficient of variation of 0.144 ) in this scale, again we find almost all of the community gardens of Burkina Faso taken into consideration in the region of Boulgou. In fact, the groups that care for these gardens demonstrate decidedly low agro-environmental abilities, in contrast with their decidedly interesting results in the social scale.

Among the gardens with higher scores in the agro-environmental scale, we find the gardens of Ghana (0.657 coefficient of variation 0.141). In the case of Rwanda, the elevated coefficient of variation demonstrates that only half of the gardens considered had high scores. In these gardens, there were positive experiences regarding the transformation and conservation of produce, the use of renewable energy, and the use of good practices for improving the management of the soil and preventing erosion. However, in general, the component that always showed the lowest values is that of biodiversity, with very low levels of crop differentiation (data not shown) testifying to strong pressures by foreign species and varieties due to agricultural politics that have not paid much attention to traditional genetic 
resources. The local potentiality is noteworthy, but much effort must still be carried out by the Slow Food network to safeguard and reinforce biodiversity, as has also been shown in a recent study on home gardens in Benin [46].

Finally, the economic scale showed an average sustainability scale equal to 0.57 with an evidently fluctuating and much more discontinuous trend (elevated coefficient of variation) in comparison to the other two scales considered. One of the aspects that most affects the variability of the results of this scale is that of the sale of produce: The sale of surplus yield, in smaller or greater proportions with respect to the entire garden crop yield, is a component that varied greatly from garden to garden and that, in some cases, was a priority for the economic sustainability of the group; meanwhile, in other cases, the only objective was food self-sufficiency.

In the case of Kenya, for example, the high coefficient of variation (0.66) showed how the Sales and Purchases components achieved good sustainability scores in only two of the involved gardens in the study. Uganda, Burkina Faso, and Rwanda also showed very high variabilities but decidedly low averages.

\section{Conclusions}

One of the key points of the "10,000 Gardens in Africa" project [34] is the integration of the agricultural experience, community sharing, and educational/outreach activities on a small urban scale. It creates part of a community, as a sharing experience. It makes it possible for different generations to come together, to exchange knowledge, and to reinforce a spirit of solidarity and friendship. At the same time, each garden makes up part of the Slow Food network of gardens. Sharing takes place not only in a single community, but between communities in the same nation, as well as between different nations. A relevant aspect in all cases is the necessity for farmers to work collectively to reinforce their ability to adapt. In the first place, the farmers can add value to their raw product through the development of collective activities, including the transformation and commercialization of foods. In this case, agroecology can provide a means through which farmers can acquire greater knowledge, in terms of the management of the environment and the consumption of healthy food. Formal and informal teaching programs in the garden serve as an important starting point for introducing as many farmers as possible to agroecological practices, such as what has already occurred in the LabVida program in Latin America [45]. Some farmers group together, in co-operatives or collective systems, in order to find a better price. They develop direct-sale strategies and, thus, move products to their consumers without intermediaries. A greater income can also compensate for the losses due to the effects of climate change, which are increasingly faced every year. Secondly, farmers can improve their collective management of natural resources; for example, with water and pastures in agro-pasture systems in semi-arid regions. It is fundamental for farmers to manage their existing resources in an efficient way, as their availability is, in general, in decline as a consequence of climate change. Finally, groups of farmers should contribute to the maintenance and transmission of traditional knowledge. In fact, farmers must come together to share knowledge on practices and systems. They can benefit from reciprocal experiences and from the results of their experimentation. Good examples are the schools on farmer's fields, which have already been established in many parts of Africa [47]. These exchange systems also provide a means for the transfer of knowledge to new generations, which has been emphasized by many NGO experts. Furthermore, according to Reijntjes et al. [48], innovations have a greater possibility of being accepted and widely adopted if they come from the people that really need them and have experience in applying them. Thus, agroecological transformation depends on a creative re-imagining of the economy, which explores the rich possibilities of a fair-trade economy, de-growth thinking, anarchic economics, and other alternatives [5]. Starting from the declaration of Nyeleni [23], it is furthermore important to underline that farmers and other citizens should practice their fundamental human rights to decide their own food and agricultural policies. As an integral part of food sovereignty, agroecology is perhaps best understood as a process that aims to expand the rule of democracy and freedom, regenerating a diversity of autonomous and socially just local food 
systems [48], such as those promoted by the "10,000 Gardens in Africa" project [34]. Nonetheless, this relocation of food systems within the region, in a view specifically addressed to urban horticulture, also requires the integration of food, energy, and water within circular systems that are able to adapt themselves to climate change [32]. This is a great challenge for agroecology, for which the projects of Slow Food seek to participate in developing and promoting radically new knowledge, derived from multi-disciplinary processes centered on the themes of food sovereignty and climate change.

Author Contributions: Conceptualization, C.P., S.M., and F.S. methodology, S.M., and C.G.; validation, C.P., C.G., and F.S.; formal analysis, C.P., S.M., and F.S.; investigation, C.P. and F.S.; data curation, C.P., S.M., and F.S.; writing-original draft preparation, C.P. and F.S.; writing-review and editing, C.P., F.S., S.M., and C.G. All authors have read and agreed to the published version of the manuscript.

Funding: This research received no external funding.

Acknowledgments: We would like to thank Piero Sardo, Serena Milano, and Raffaella Ponzio from the Slow Food International Foundation for Biodiversity for assisting with the collection of data and for having participated in a critical discussion. We would also like to thank all of the producers, professionals, colleagues, and collaborators that actively participated in the research project as well as all of the personnel of the Slow Food International offices that helped us to retrieve the data and without whom this project would not have been possible.

Conflicts of Interest: The authors declare no conflict of interest

\section{References}

1. FAO. Scaling up Agroecology Initiative: Transforming Food and Agricultural Systems in Support of the SDGs; Food and Agriculture Organization of the United Nations: Rome, Italy, 2018.

2. Levidow, L.; Pimbert, M.P.; Vanloqueren, G. Agroecological research: Conforming-Or transforming the dominant agro-food regime. Agroecol. Sustain. Food Syst. 2014, 38, 1127-1155. [CrossRef]

3. Royal Society. Reaping the Benefits: Science and the Sustainable Intensification of Global Agriculture; The Royal Society: London, UK, 2009.

4. Altieri, M.A.; Nicholls, C.; Montalba, R. Technological approaches to sustainable agriculture at a crossroads: An agroecological perspective. Sustainability 2017, 9, 349. [CrossRef]

5. Pimbert, M.P. Global status of agroecology: A perspective on current practices, potential and challenges. Econ. Political Wkly. 2018, 53, 52-57.

6. Hernández Xolocotzi, E. Contribuciones a la Enseñanza, Investigación y Divulgación Agrícola; Agroecosistemas de México: Chapingo, Mexico, 1977.

7. Altieri, M.A. Agroecology: The Scientific Basis of Alternative Agriculture, Boulder; Westview Press: Boulder, CO, USA, 1987.

8. Gliessman, S. Agroecology: Roots of resistance to industrialised food systems. In A Transdisciplinary, Participatory and Action-Oriented Approach; Méndez, V.E., Bacon, C.M., Cohen, R., Gliessman, S.R., Eds.; CRC Press: Boca Raton, FL, USA, 2015.

9. Rabhi, P. L'offrande au crepuscule. In Candide; Lavilledieu, G.C., Ed.; L'Hamarttan: Paris, France, 1989.

10. Francis, C.; Lieblein, G.; Gliessman, S.; Breland, T.A.; Creamer, N.; Harwood, R.; Salomonsson, L.; Helenius, J.; Rickerl, D.; Salvador, R.; et al. Agroecology: The ecology of food systems. J. Sustain. Agric. 2003, 22, 99-118. [CrossRef]

11. Gliessman, S.R. Agroecology: The Ecology of Sustainable Food Systems, 3rd ed.; CRC Press, Taylor and Francis Group: Boca Raton, FL, USA, 2015.

12. Holt-Giménez, E. Measuring farmers' agroecological resistance after hurricane mitch in Nicaragua: A case study in participatory, sustainable land management impact monitoring. Agric. Ecosyst. Environ. 2002, 93, 87-105. [CrossRef]

13. Francis, C.A.; Wezel, A. Agroecology and Agricultural Change. In Wright, International Encyclopedia of the Social and Behavioral Sciences, 2nd ed.; Elsevier: Amsterdam, The Netherlands, 2015; pp. 484-487.

14. Aguilar, Y.; Calero, B.; Rodriguez, D.; Muniz, O. Cuba's polygon program—Agricultural land rehabilitation. Curr. Opin. Environ. Sustain. 2015, 15, 72-78. [CrossRef]

15. Lowder, S.K.; Skoet, J.; Raney, T. The number, size, and distribution of farms, smallholder farms, and family farms worldwide. World Dev. 2016, 87, 16-29. [CrossRef] 
16. Saghir, J. Global challenges in agriculture and the World Bank's response in Africa. Food Energy Secur. 2014, 3, 61-68. [CrossRef]

17. Valentini, R.; Arneth, A.; Bombelli, A.; Castaldi, S.; Cazzolla Gatti, R.; Chevallier, F.; Ciais, P.; Grieco, E.; Hartmann, J.; Henry, M.; et al. A full greenhouse gases budget of Africa: Synthesis, uncertainties, and vulnerabilities. Biogeosciences 2014, 11, 381-407. [CrossRef]

18. Ba, M.N. Analysis of agricultural commodities value chains and greenhouse gas emission in rice and maize in West Africa: Impact on food security. Agric. Sci. 2016, 7, 457-468.

19. Tongwanea, M.I.; Moeletsia, M.E. A review of greenhouse gas emissions from the agriculture sector in Africa. Agric. Syst. 2018, 166, 124-134. [CrossRef]

20. Chauvin, D.C.; Mulangu, F.; Porto, G. Food production and consumption trends in sub-Saharan Africa: Prospects for the transformation of the agriculture sector. In Working Paper WP 2012-011. Regional Bureau for Africa; United Nations Development Programme: New York, NY, USA, 2012.

21. Tadele, Z. Raising crop productivity in Africa through intensification. Agronomy 2017, 7, 22. [CrossRef]

22. Rabhi, P. Manifeste pour la terre et l'humanisme: Pour une Insurrection des Consciences; Actes Sud: Arles, France, 2011.

23. Declaration of the International Forum for Agroecology, Nyéléni, Mali: 27 February 2015. Development 2015, 58, 163-168. [CrossRef]

24. Posey, D.A. Cultural and spiritual values of biodiversity: A complementary contribution to the Global Biodiversity Assessment. In Cultural and Spiritual Values of Biodiversity; Posey, D.A., Ed.; United Nations Environmental Programme and Intermediate Technology Publications: London, UK, 1999; pp. 1-19.

25. IPCC. The IPCC's Fifth Assessment Report: What's in it for Africa. In Executive Summary; Cambridge University Press: Cambridge, UK; New York, NY, USA, 2014.

26. Debray, V.; Wezel, A.; Lambert-Derkimba, A.; Roesch, K.; Geir Lieblein Francis, C.A. Agroecological practices for climate change adaptation in semiarid and sub humid Africa. Agroecol. Sustain. Food Syst. 2019, 43, 429-456. [CrossRef]

27. Bezner Kerr, R.; Nyantakyi-Frimpong, H.; Dakishoni, L.; Lupafya, E.; Shumba, L.; Luginaah, I.; Snapp, S.S. Knowledge politics in participatory climate change adaptation research on agroecology in Malawi. Renew. Agric. Food Syst. 2018, 33, 238-251. [CrossRef]

28. Rogé, P.; Diarisso, T.; Diallo, F.; Boiré, Y.; Goïta, D.; Peter, B.; Macalou, M.; Weltzien, E.; Snapp, S. Perennial grain crops in the West Soudanian Savanna of Mali: Perspectives from agroecology and gendered spaces. Int. J. Agric. Sustain. 2017, 15, 555-574. [CrossRef]

29. Isgren, E.; Ness, B. Agroecology to promote just sustainability transitions: Analysis of a civil society network in the Rwenzori Region, Western Uganda. Sustainability 2017, 9, 1357. [CrossRef]

30. La Via Campesina, The Maputo declaration, Maputo, Mozambique. Available online: https://viacampesina. org/en/declaration-of-maputo-v-internation-al-conference-of-la-via-campesina/ (accessed on 15 February 2020).

31. Gómez-Pompa, A.; Kaus, A. Taming the Wilderness Myth: Environmental Policy and Education Are Currently Based on Western Beliefs about Nature Rather than on Reality. Bioscience 1992, 42, 271-279.

32. Petrini, C. Buono, Pulito e Giusto: Principi di Nuova Gastronomia; Einaudi: Torino, Italy, 2005.

33. Sottile, F.; Peano, C. Agricoltura Slow; Slow Food Editore: Bra, Italy, 2017.

34. Slow Food Foundation for Biodiversity. Available online: https://www.fondazioneslowfood.com/en/category/ 10000-gardens-in-africa/ (accessed on 15 February 2020).

35. Peano, C.; Tecco, N.; Dansero, E.; Girgenti, V.; Sottile, F. Evaluating the sustainability in complex agri-food systems: The SAEMETH framework. Sustainability 2015, 7, 6721-6741. [CrossRef]

36. Sottile, F.; Fiorito, D.; Tecco, N.; Girgenti, V.; Peano, C. An interpretive framework for assessing and monitoring the sustainability of school gardens. Sustainability 2016, 8, 801. [CrossRef]

37. Van Calker, K.; Berentsen, P.; de Boer, I.; Giesen, G.; Huirne, R. An LP-model to analyze economic and ecological sustainability on Dutch dairy farms: Model presentation and application for experimental farm de Marke. Agric. Syst. 2004, 82, 139-160. [CrossRef]

38. Meul, M.; van Passel, S.; Nevens, F.; Dessein, J.; Rogge, E.; Mulier, A. 2008 MOTIFS: A monitoring tool for integrated farm sustainability. Agron. Sustain. Dev. 2008, 28, 321-323. [CrossRef]

39. Terra Madre. Available online: https://www.terramadre.info/en/ (accessed on 15 February 2020). 
40. Williams, D.R.; Dixon, P.S. Impact of garden-based learning on academic outcomes in schools synthesis of research between 1990 and 2010. Rev. Educ. Res. 2013, 83, 211-235. [CrossRef]

41. Ghana School Feeding Program. Available online: http://schoolfeeding.gov.gh/ (accessed on 15 February 2020).

42. Stambach, A. Food, aid, and education in East Africa: Repackaging the conversation. Camb. J. Educ. 2016, 46, 247-262. [CrossRef]

43. Bowker, R.; Tearle, P. Gardening as a learning environment: A study of children's perceptions and understanding of school gardens as part of an international project. Learn. Environ. Res. 2007, 10, 83-100. [CrossRef]

44. Roberts, S.; Shackleton, C. Temporal dynamics and motivations for urban community food gardens in medium-sized towns of the Eastern Cape, South Africa. Land 2018, 7, 146. [CrossRef]

45. Ferguson, B.G.; Morales, H.; Chung, K.; Nigh, R. Scaling out agroecology from the school garden: The importance of culture, food, and place. Agroecol. Sustain. Food Syst. 2019, 43, 724-743. [CrossRef]

46. Gbedomon, R.C.; Salako, V.K.; Adomou, A.C.; Kakaï, R.G.; Assogbadjo, A.E. Plants in traditional home gardens: Richness, composition, conservation and implications for native biodiversity in Benin. Biodivers. Conserv. 2017, 26, 3307. [CrossRef]

47. Tibasiima, T.; Nalunga, J.; Vaarst, M.; Dissing, I.L. Farmer family learning groups in Uganda. In Organic Agriculture: African Experiences in Resilience and Sustainability; FAO: Rome, Italy, 2013; pp. 162-177.

48. Reijntjes, C.; Haverkort, B.; Waters-Bayer, A. Farming for the Future; Macmillan Education: London, UK, 1992.

(C) 2020 by the authors. Licensee MDPI, Basel, Switzerland. This article is an open access article distributed under the terms and conditions of the Creative Commons Attribution (CC BY) license (http://creativecommons.org/licenses/by/4.0/). 